\title{
Erasures, Transgressions, and Demarcations: Site Tactics for the Post-Internet City
}

\author{
ZACHARY TATE PORTER \\ University of Nebraska-Lincoln
}

The contemporary city is an increasingly homogenous environment shaped by the combined forces of investment, gentrification, and displacement. While many speculated that the integration of digitally-networked technologies would make the city more equitable and transparent, such a promise has not been delivered. In this context, architecture must reevaluate its role in the future development of urban space. This paper frames these dynamics through a discussion of urban site tactics, examining the formal articulation of architecture's relationship to the city. Drawing upon examples from architecture, technology, and art, three specific tactics are introduced and evaluated: erasure, transgression, and demarcation. Ultimately, the paper argues for strategies of demarcation, which emphasize-rather than obscure-the fundamental difference between public and private space.

\section{INTRODUCTION}

Driving into Downtown Los Angeles, taking the 4th Street exit from the Harbor Freeway, one encounters the unavoidable presence of John Portman's Westin Bonaventure reflecting a fragmented spectrum of slate, violet, and amber. As many critics have pointed out, the building was designed to be seen this way: from afar, inside of a moving automobile. Constructed in 1974, the hotel's five mirrored towers sit atop a massive concrete podium that creates a fortress-like barrier between its interior and the city beyond. Such an urban posturing prompted Fredric Jameson to famously characterize the building as "a total space, a complete world, a kind of miniature city." ${ }^{1}$ As Jameson put it, the Westin Bonaventure "does not wish to be part of the city but rather its equivalent and replacement or substitute."2 Unsurprisingly, the building's lack of urban engagement at the street level has elicited harsh critiques from a variety of detractors over the past few decades. Nonetheless, Portman's Westin Bonaventure serves as a productive site to unpack the relationship between architecture and the city during the postwar era.

For better or worse, the Westin Bonaventure reflects the social and cultural milieu in which it was produced. In the decades following World War II, American cities became the de facto sites for a variety of social, political, and economic crises. The compounding effects of deindustrialization, white flight, and racial unrest, among numerous other dynamics, contributed to the American public's bleak outlook on urban environments. By the late 1960s, the city had been recast as a dystopia within the public imagination-a dangerous

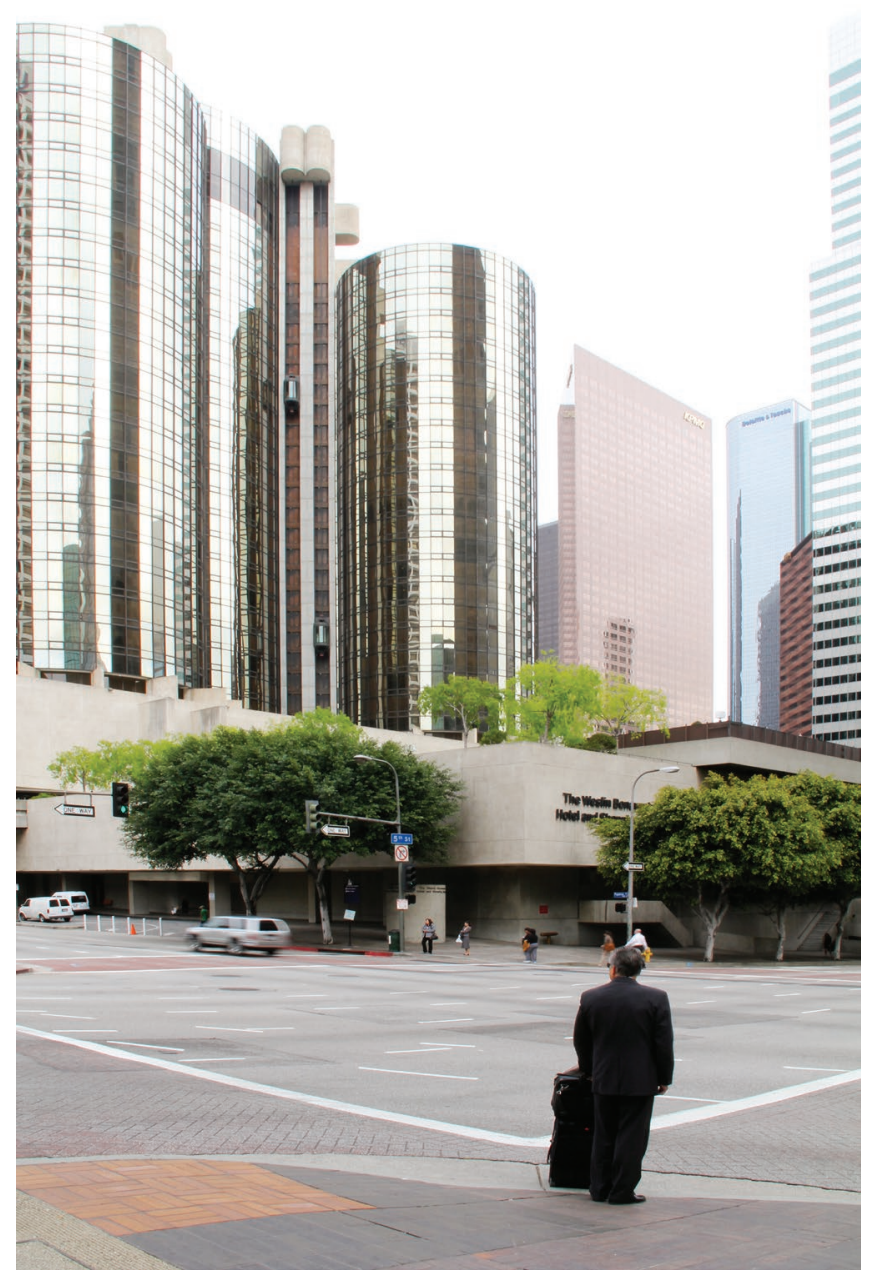

Figure 1. John Portman's Westin Bonaventure Hotel in Downtown Los Angeles. Credit: Erica Chang.

environment animated by crime, tension, and degeneracy. Meanwhile, American architects discovered that they were no longer in a position to offer comprehensive design solutions for the so-called "urban crisis." 3 The emergence of professional planners during the first half of the twentieth century dramatically curtailed architecture's role in proposing and reshaping large urban systems. Such a transformation aligned city planning with public policy and governmental regulation, effectively shifting the mindset from qualitative outcomes to quantitative instrumentalities. Having lost their jurisdiction over the urban whole, American architects were forced to focus their efforts on the urban piece. Considering the fact that this gradual loss of jurisdiction in the area of city 
planning was paired with a generally negative perception of cities during the postwar era, it should not be so surprising to find buildings-like the Westin Bonaventure-that close off their interior spaces from the surrounding city. Such a contextual reading of the Bonaventure is not intended to justify or valorize its urban strategy, but instead to serve as a reminder of how dramatically the American city has shifted once again since the postwar era.

The contemporary city bears almost no resemblance to the dystopian rhetoric that pervaded postwar discussions of the urban environment. Over the past decade, the combined forces of revitalization, gentrification, and foreign investment have reshaped both the formal and sociological composition of American cities. At the same time, the cultural ubiquity of mobile technologies and social media, as well as various forms of political protest, have overlaid an additional set of behaviors and sensibilities onto urban space. Yet, as was the case during the postwar era, the architect's jurisdiction remains limited to the scale of the single building. That being so, one might expect the discipline to have developed a robust discourse on potential site strategies and tactics for urban contexts. However, such a discourse has not materialized as of yet. In fact, many contemporary critics and theorists express a complete lack of interest in discussions of site, viewing the subject as outdated, irrelevant, or otherwise obsolete. In contrast to such an apparent consensus, this paper proposes a return to site within architectural discourse-a return that would replace romantic notions of authenticity and place-making, which dominated site discourse in the 1980s, with an attentiveness to the socio-political implications of architectural form within the urban environment. To this end, three specific formal tactics-erasure, transgression, and demarcation-are described and analyzed through a series of case studies ranging from architecture and art to digital and internet-based technologies. Ultimately, the paper argues that architecture's limited jurisdiction in city planning-its confinement to the space of a single building site-presents an opportunity to operate critically against the growing homogeneity of contemporary urbanism.

\section{THE FORMAL-TECHNOLOGICAL LENS}

Identifying erasure, transgression, and demarcation as architectural tactics within the urban environment raises an important question: what exactly is being erased, transgressed, or demarcated? To answer this question simply, it is the site boundary itself that is being acted upon by these three verbs. The longer, more complex answer, however, requires some background context on the historical composition of the American city and its ideological roots. Since the Colonial Period, American cities have relied upon a clear division between the public and private spheres of urban life. Such a division is clearly articulated, for instance, in James Oglethorpe's plan for Savannah and William Penn's plan for Philadelphia (figure 2). Each of these plans features an

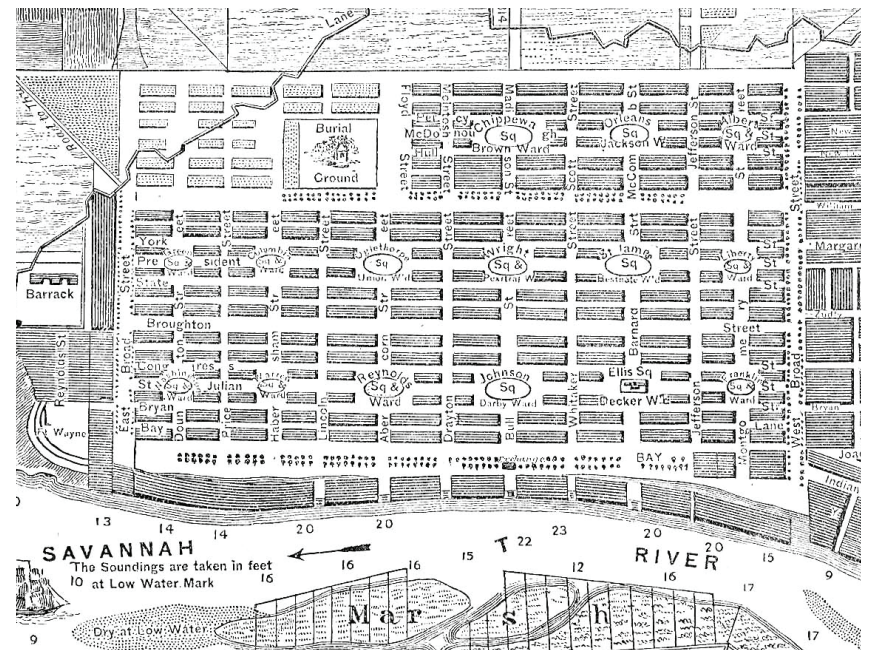

Figure 2. 1818 Map of Savannah illustrating James Oglethorpe's plan

orthogonal street grid populated with rectangular blocks and a series of open squares. Significantly, these squares were conceived as political spaces for public dialogue and debatea prospect that was intimately connected to the project of America itself. While not all American cities were planned in such a rational manner, the general diagram remains consistent: there are streets and open spaces (i.e. parks, town squares, etc.) that form the public framework for the city, and then there are private parcels within the street grid occupied by buildings of various sizes and functions. Of course, such a diagram is by no means an American invention as its basic elements can be traced back to Roman city planning. Nonetheless, this formal logic and the ideological motivations behind it provide a critical framework for evaluating the historical development and future trajectory of American urbanism. Under such a framework, it becomes clear that the boundary defining an architectural site is one and the same with the boundary that divides private from public within the urban environment. Thus, the act of erasing, transgressing, or demarcating that division is inherently charged with myriad socio-political implications. So, while the subsequent analysis focuses explicitly on the formal character of architecture its urban adjacencies, the point is not fetishize form for its own sake. Instead, form is understood as the primary medium through which architecture negotiates its relationship to the city as a whole. ${ }^{4}$

Of course, it is impossible to dissect the relationship between private and public spheres of urban life without some consideration for internet-based technologies, which have fundamentally reshaped contemporary society and cultural products. Two decades into the new millennium, one might even characterize the American urban environment as a "post-internet" city. This term, borrowed from art discourses, does not imply a city without or after the internet, but instead, one in which digitally-networked technologies are so completely embedded and integrated into urban 
life that it is no longer meaningful to distinguish them from other aspects of the urban environment. In this sense, the digitally-networked technologies of the post-internet city are not valued for their own novelty, but rather according to the qualities of urban engagement that they facilitate. In the following analysis of erasure, transgression, and demarcation, commentary on internet-based technologies (and the socio-political relationships they enable) is integrated into discussions of urban site dynamics. As will be shown, architects stand to learn from these digitally-networked systems as their limitations and problematics offer key insights into the larger implications of erasing, transgressing, or demarcating the physical division between public and private space. Yet, while each of these three site tactics will be given equal analysis, only one-demarcation-will ultimately be supported as an effective response to the challenges presented by the post-internet city.

\section{ERASURE}

During the postwar development of American art, acts of erasure came to be seen as creative endeavors in their own right. ${ }^{5}$ At the same moment that John Portman was preparing the preliminary plans for his fortress-like Westin Bonaventure, for instance, the conceptual artist, Michael Asher, was exploring an oppositional approach by erasing the boundary between interior and exterior. Asher's 1970 untitled installation at Pomona College required the construction of several new walls inside the Gladys K. Montgomery Art Center and, most importantly, the removal of the doubledoors that control access through the main entrance of the building. With this erasure of the traditional boundary between inside and outside, Asher radically transformed both the spatial and temporal nature of the gallery environment, opening it up the public on a twenty-four-hour basis for the full run of the exhibition. For Asher, this kind of erasure would become a recurring theme in his site-specific installation work. In 1974, for instance, he famously removed a wall separating the exhibition space from the business office in the Claire S. Copley Gallery in Los Angeles. Distinct from his minimalist contemporaries who emphasized the objecthood of form, Asher refocused attention on the tangle of immaterial forces-sound, light, time, economies, sociologies, and so onthat operate upon and flex in response to formal and spatial arrangements. In this sense, his erasures do not emphasize the formal qualities of their resulting voids-as in the work of Gordon Matta Clark, for instance-so much as they redefine the relationship between architectural space and its social and phenomenological inhabitation. ${ }^{6}$

If Asher's installation work illustrates the subversive potential of erasure-deployed, in his case, as a mode of institutional critique-then the emergence of digital and internet-based technologies during the 1990 s created the possibility for such subversive erasures to occur at the planetary scale. Like Asher's subtractive installations, the internet promised to dismantle barriers established by traditional hierarchies, while also collapsing the divisions between distant geographies. In short time, many cultural critics foretold, the internet would all but eliminate existing economic structures and nation-state boundaries, replacing them with smooth networks and flows capable of melding distributed societies into a single, global culture. The emergence of social media in the early 2000s was met with similar optimism as a seemingly unanimous collective heralded its potential to democratize information.

Within architecture, the optimism surrounding digital and internet-based technologies spawned novel formal vocabularies-continuous surfaces, swarms, and folds, to name a few-which signaled a fundamental shift in how architects imagined their work and its relationship to the contemporary city. Eschewing traditional divisions between public and private space, many architects of the first digital turn sought to blur, blend, soften, or otherwise camouflage the physical boundary between architecture and its surrounding context. While such an approach was initially confined to speculative projects, it has more recently become manifest in the parallel movements of Landform Building and Landscape Urbanism, which promote the hybridization of buildings, landscapes, and cities. In these projects, such as Weiss/Manfredi's Olympic Sculpture Park and FOA's Yokohama Port Terminal, among countless others, architecture fuses with the urban ground to form a single, continuous entity.

Unfortunately, the unbridled optimism that flourished during the early digital age was premature. While the integration of flows and networks into everyday life-via social media-and architectural practice-via digital tools-were initially seen as critical steps forward, each of these cultural projects has had its own unintended and undesirable consequences. Despite its promise to democratize information and obliterate the distances between geographies and cultures, social media has been instrumentalized for other purposes. Its smoothing tendencies have been used to sway elections and obscure distinctions between fact and fiction, catapulting its users into echo chambers that undermine the credibility of our institutions. Meanwhile, architecture's recent attempts to erase the boundary between building and city-through the formal vocabulary of continuous surfaces and gradient networksnever achieved the degree of criticality reflected in Michael Asher's installation work. In actuality, these architectural gestures are not erasures at all so much as they are suppressions, concealments, or obfuscations. They offer only the illusion of continuity since the traditional frameworks for urban spacei.e. the legal definitions of public and private property-are typically still at work in these settings. In other words, these continuous landform projects do not reclassify architecture as part of the public realm (in the legal sense), but instead, construct only the appearance of smoothness and flow between buildings and their surrounding urban environments. Such 
attempts to disguise the boundary between architecture and the city are problematic, because they mis-represent the real and significant differences between public and private space. At their worst, these projects facilitate the propagation of private spaces masquerading as public ones-a phenomenon with a name, Privately Owned Public Spaces (POPS), and a long list of detractors within the field of urban sociology. ${ }^{7}$ Since these ostensibly public spaces are patrolled and policed by private security forces, they open up the possibility for a wide range of concerning dynamics, including the exclusion of non-conforming behaviors and bodies. ${ }^{8}$ In this sense, the technologies and techniques of erasure, which once held such critical and subversive potential, now operate as forces of homogenization and misinformation within the contemporary urban environment.

\section{TRANSGRESSION}

Having established the problems associated with erasing-or more accurately, disguising-the boundaries that define an urban site, one might wonder what potentials lie in transgressing those boundaries and venturing out into spaces where architecture does not belong. After all, the twentieth century has shown transgression to be an effective mode of political engagement. Consider, for instance, the Los Angeles art collective, Asco, which deployed street art tactics to explore issues affecting the Chicano community during the 1970s and 1980s. Their 1974 performance, First Supper (After a Major Riot), took the form of a costumed dinner party (featuring masks, skeletons, and mannequins) staged on the median subdividing Whittier Boulevard-the same road where Chicano anti-war protesters clashed with LA Police only a few years earlier. By occupying the median in such a performative manner, the group sought to reclaim public space as domain of political visibility. Such a gesture was especially provocative given the fact that the inhabitation of public space had been criminalized only a few years earlier through city-wide curfews, which were imposed as a response to the 1970 Chicano Moratorium. ${ }^{9}$

Shifting to the contemporary, the last decade has demonstrated the ways in which strategies of transgression still hold a central place within the cultural psyche. In 2011, for instance, Time Magazine named the proverbial "protester" as their "Person of the Year." At the time, social media was seen as a crucial ally to grass-roots resistance movements. Numerous scholars have commented, for instance, on the ways in which Facebook and Twitter undergirded the "Arab Spring." 10 Using these social media platforms, organizers were able to share critical information-such as the locations and timelines for future protests-without being censored by authoritarian governments. In the United States, the Occupy Wall Street movement of 2011 also relied heavily upon digital technologies and social media to build momentum. The multitude of Facebook posts, Tweets, and YouTube videos depicting the events served as a proxy (but not a replacement) for urban engagement and collective protest.
As a parallel to these currents of political resistance, many architects and designers have developed their own transgressive means for occupying the city during this new millennium. Such efforts are often framed through the concepts of "gurellia" and "tactical" urbanism, which remain quite popular within many schools of architecture today. ${ }^{11}$ Perhaps the most well-known example of the kind is "Park(ing) Day," an event that started in November 2005 when the San Francisco-based studio, Rebar, converted a metered parking space within the city's SOMA district into a small temporary park. Such a gesture was intended as a critique of American urbanism and, especially, its disproportionate allocation of space to the automobile. In the years since, the strategy has been adopted by thousands of other architects across the globe, who now design and construct their own urban micro-environments on a designated date in late September (figure 3). Within the context of this paper, the intriguing dynamic is the way in which these architectural transgressions defy the traditional structure of urban space by placing architecture outside of its bounded site, thereby, clouding distinctions between the public and private spheres of the city.

As in the case of erasure, however, there are limitations and drawbacks associated with acts of transgression. For instance, recent current events-from the Charlottesville "Unite the Right Rally" to WikiLeaks' release of sensitive national security information-have demonstrated how transgressive tactics are susceptible to misuse. Moreover, while social media was initially seen as a tool for resistance, many commentators have since acknowledged its tendencies to reinforce-rather than disrupt-hegemonic structures. Adam Greenfield, for instance, argues that the "ostensibly utopian smart city [is] nothing more than the information-technological aspect of a globally triumphant but still-ravenous neoliberalism." ${ }^{\prime 2}$ As a key example, Greenfield points to Uber and several of its underlying premises: "Those who can afford to pay more deserve to be treated better."; "The cost of convenience can be borne by drivers or shed onto the communities in which the service operates."; and "Private enterprise should be valorized over public service provision on principle, even when public alternatives would afford comparable levels of service." ${ }^{13}$ Through Greenfield's analysis of these premises, it becomes clear that any blind faith in social media's transgressive potential is both naïve and misinformed. The same platforms that once facilitated resistance to authoritarian governments abroad now represent multibillion dollar corporations, which threaten the future of privacy by using increasingly sophisticated methods of collecting, parsing, and sharing user information, all while making the urban centers they inhabit completely unaffordable to working populations.

Within architecture, the limitations of so-called "guerilla" and "tactical" urbanism are also evident. An event like Park(ing) Day, for instance, hardly resembles anything close to transgressive resistance. Instead, these kinds of temporary interruptions of the urban order function more like 


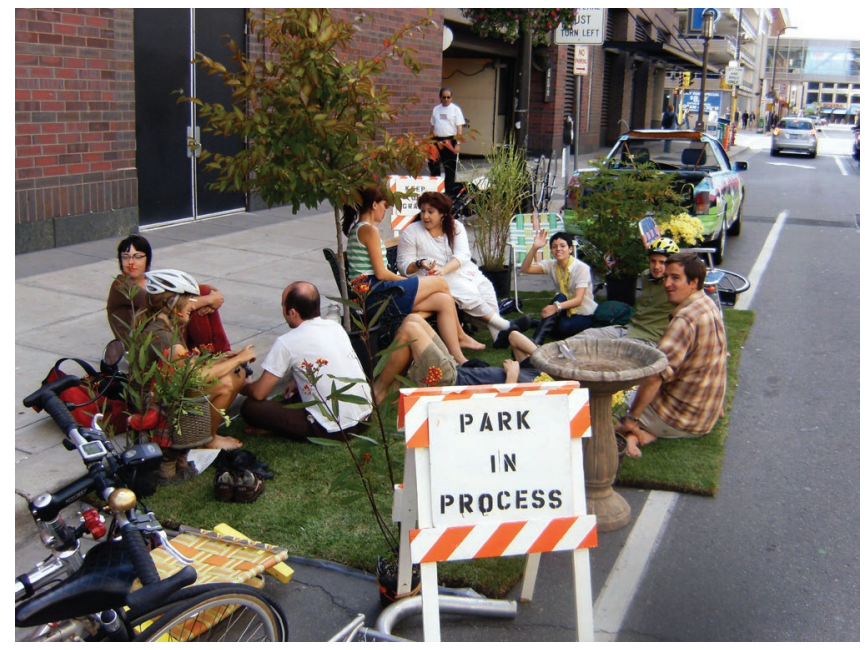

Figure 3. National Park(ing) Day in Minneapolis, 2008. Credit: SV Johnson.

carnivalesque festival. And, as Terry Eagleton has pointed out, the carnivalesque cannot be a mode of resistance, because it is "licensed in every sense" by dominant culture. ${ }^{14}$ Extending Eagleton's analysis to "guerilla" and "tactical" urbanism, one might interpret these trends as a "permissible rupture of hegemony" intended to release pressure rather than enact large-scale societal change. ${ }^{15}$ By side-stepping the fundamental structure of urban space-i.e. the division of public and private space-these "transgressive" projects distract the discipline from sincere efforts to theorize and enact critical strategies that are both substantive and widely applicable.

\section{DEMARCATION}

Whereas the examples of Asco and Michael Asher illustrate the critical potential of transgression and erasure as creative tactics, their translations into twenty-first century contexts have revealed numerous pitfalls and limitations. On the one hand, it has become all too obvious that transgressive tactics can be subsumed into the logics of neoliberal hegemony. Consider, for instance, Kendall Jenner's much-maligned Pepsi commercial in which she (along with the corporate sponsor and advertisement production team) appropriates protest culture-particularly that of the Black Lives Matter movement-to sell soft drinks. Meanwhile, social media has demonstrated that the dissolution of boundaries can have a negative impact on society at large, eroding distinctions between fact and fiction, between news and opinion, between content and advertisement. Or, to use a different example from contemporary society, the emerging typology of "work-is-fun" office environments-with its ping-pong tables, craft beer taps, and sleeping pods-has many millennials longing for a clearer boundary between work and life. Within such a cultural context, the return to demarcation need not be seen as a reinforcement of old hierarchies, but instead, as a means for generating new, more equitable frameworks for contemporary life. In this sense, it is radical to have boundaries and to hold to them.
Within architectural discourse, emerging practitioners like Gilles Retsin and Jose Sanchez have argued for discreteness at the architectonic scale. By rejecting the "illusion of continuity"-an idea that was propagated by architects of the first digital turn (see parametricism)-these emerging architects are cogently re-evaluating the role of digital tools within architectural production. ${ }^{16}$ This paper seeks to build upon these arguments for discreteness by applying the concept to the urban scale. Such a position does not, however, imply a return to the site strategies epitomized by John Portman's Westin Bonaventure in which the building closes itself off from city in order to create its own internalized world. On the contrary, this final section contends that demarcation can operate as a strategy of urban engagement, rather than isolation. Thus, the kinds of demarcations supported here are not those intended to fully enclose or divide. Instead, this paper aims to promote discourse and speculation on a taxonomy of forms-stages, windows, thresholds, joints, and so on-through which architecture might interface with the urban realm while also demarcating its difference from the city proper.

While a comprehensive taxonomy of discrete urban interfaces is obviously beyond the scope of this paper, one example-the constructed plinth-illustrates how architectural demarcation promotes (rather than discourages) urban engagement. In William H. Whyte's classic film, The Social Life of Small Urban Spaces, Mies van der Rohe's Seagram Plaza is heralded as an exemplary space for interaction within New York City. Through empirical observation and correlational analysis, Whyte and his team of researchers attribute the plaza's success to its edges, where raised steps and ledges allow users to gather and converse while taking in the scenes of everyday urban life from its front row. In his 2011 book, The Possibility of an Absolute Architecture, Pier Vittorio Aureli reiterated Whyte's conclusion, albeit through a quite different mode of analysis. Theorizing the affective qualities of Mies' work, Aureli comments on the plinth's tendency to remove its inhabitants from the psychological space of the city. "Suddenly, and for a brief moment," Aureli notes, "one is estranged from the organizational patterns that animate the city, yet still confronting them." ${ }^{17}$ Together, Aureli's theorizations and Whyte's observations reinforce the point that architecture's agency within the urban environment relies upon a clear demarcation of its difference from and boundary with the city proper. In the case of the Seagram plaza, such a demarcation is produced by an extrusion of the ground plane-an extrusion that creates a space from which to see the city anew. ${ }^{18}$ But regardless of how the division of architecture and city is made manifest, the key point is that such a demarcation should function as an interface-rather than a barrier-between the private and public realms of urban life.

It should be noted that this argument for architectural discreteness within the urban realm is not necessarily new or revolutionary. In fact, a number of practitioners and theorists-most notably, Aldo Rossi-have described architecture's capacity to operate autonomously from and, therefore, 


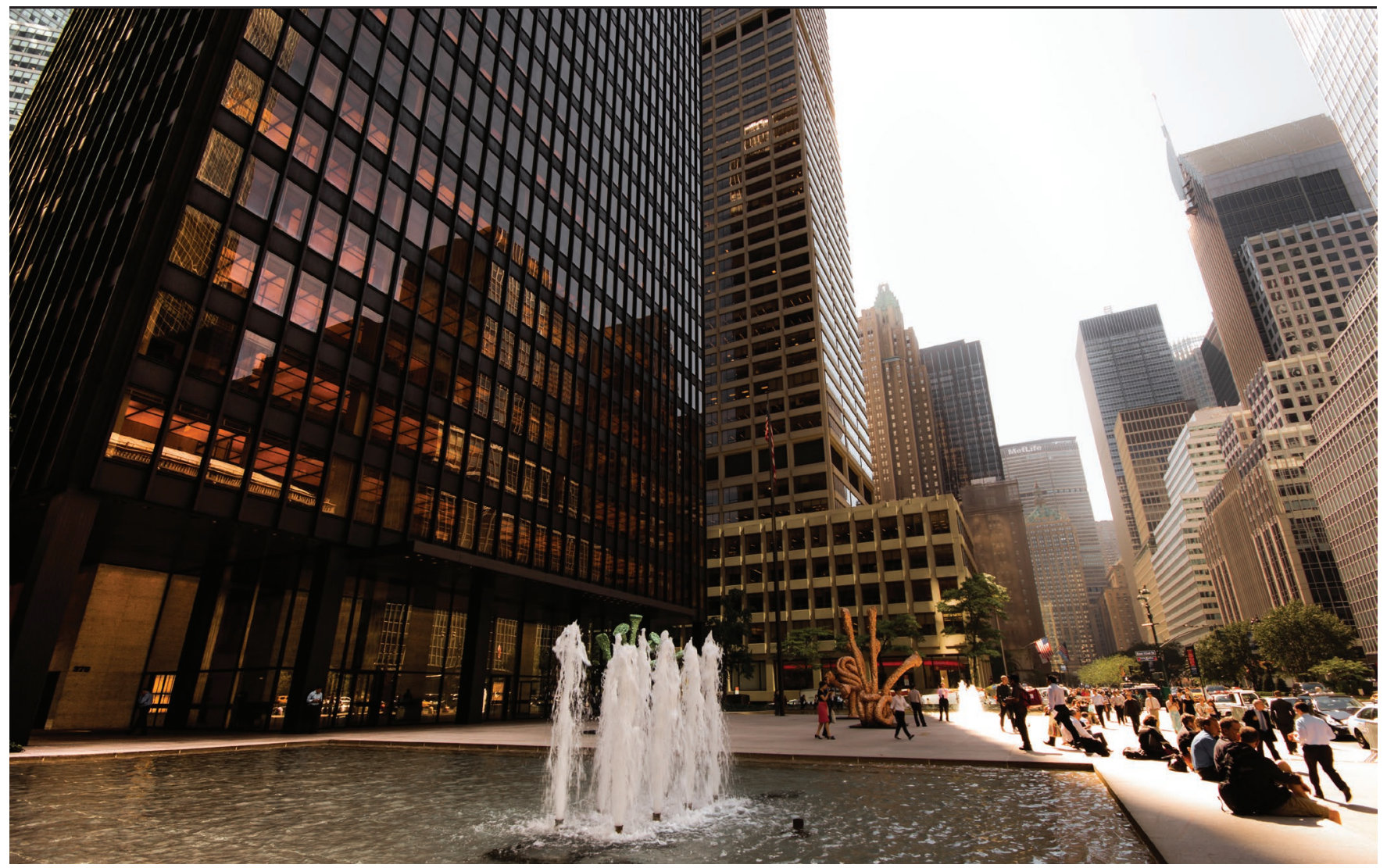

Figure 4. People gathered along the edge of the Seagram Building's raised plaza in New York City. Credit: Alex Schwab.

critically against the modern city. ${ }^{19}$ In her landmark text, The Death and Life of Great American Cities, Jane Jacobs makes the point explicitly: "First, there must be a clear demarcation between what is public space and what is private space. Public and private spaces cannot ooze into each other as they do typically in suburban settings."20 These older variants of the argument notwithstanding, demarcation takes on renewed importance in the post-internet city where the combined forces of gentrification, investment, and corporate surveillance threaten to replace the city's inherent tensions and difference with an array of increasingly homogeneous environments.

\section{CONCLUSION}

At the beginning of the twenty-first century, many speculated that digital networks and flows would radically disrupt the primacy of physical space. In some ways, these commentators were right. Social media and other web-based communication platforms routinely supersede nation-state borders by facilitating the exchange of ideas, products, and currencies across the globe in real-time. In other ways, however, physical space has retained its traditional importance with some geopolitical boundaries becoming even more apparent in the post-internet era. One need only look to the contested borders that divide Russia from Ukraine, or Israel from the West Bank, or the United States from Mexico for evidence such a point. Furthermore, while social media platforms like Twitter and Facebook were indeed instrumental to political resistance during the Arab Spring and Occupy Wall Street protests, it was only in the physical occupation of public spaces that these movements gained international attention. This realization, along with the examples of Ferguson and Charlottesville, as well as the 2017 Women's March, support the conclusion that digital technologies have amplified-rather than diminishedthe socio-political role of the city. As it turns out, physical space has not dematerialized into digital bits.

Even as digitally-networked technologies become embedded in the urban environment, physical space continues to shape meaningful relationships and interactions. For this reason, a reconsideration of architecture's formal relationship to the contemporary city is long overdue. Through the triad of erasure, transgression, and demarcation, this paper highlights the sociopolitical implications architectural site tactics within the urban realm, especially their articulation of the boundary between private and public space. Accepting the premise that architects work at the scale of the urban piece, rather than the urban whole, this paper argues for discreteness, emphasizing the social value of defined limits and edges. While such an approach stands in sharp contrast to recent calls for interdisciplinarity, hybridization, and collaboration across the design disciplines, it nonetheless represents the most effective tactic for countering the homogenizing forces of contemporary urbanism. 


\section{ENDNOTES}

1 Frederic Jameson, Postmodernism, or The Cultural Logic of Late Capitalism (Durham: Duke University Press, 1991), 40.

2 Jameson, 40.

3 For a thorough analysis of the "urban crisis" and its contributing factors, see Thomas Sugrue, The Origins of the Urban Crisis: Race and Inequality in Postwar Detroit (Princeton: Princeton University Press, 1996).

4 It should be noted that this formal lens is merely one of many analytic frameworks that can be applied to urban site relationships. Within landscape theory, for instance, sites are often characterized as thick and dynamic systems, which participate in multiple scales of social, technological, and ecological performance. This paper's focus on form is not intended to negate these more dynamic discussions of site. Instead, the intent is to illustrate how complex socio-cultural and political relationships are both facilitated by and represented in the physical articulation of architecture's boundary conditions.

5 See for instance, Robert Rauschenberg's Erased de Kooning Drawing (1953), or Ronald Johnson's Radi os (Chicago: Flood Editions, 2005), or Gordon Matta Clark's subtractive interventions in abandoned buildings.

6 Such an interpretation of Matta Clark's work reflects the conventional understanding established within the discourse. However, Mark Wigley has convincingly argued against such an interpretation in a recent lecture, entitled "Anarchitecture 101.5 - Cutting Matta-Clark," delivered at SCl-Arc in September 2017.

7 For more on this phenomenon, see Setha Low and Neil Smith, eds., The Politics of Public Space (New York: Routledge, 2006); and Jeremy Németh and Stephen Schmidt, "The Privatization of Public Space: Modeling and Measuring Publicness," Environment and Planning B: Urban Analytics and City Science 38, no. 1 (February 2011): 5-23.

8 Sarah Whiting has also commented on the homogenizing effects of privatizing of "public space" in reference to urban beaches in Los Angeles. See, Sarah Whiting, "Lines Drawn in Sand: The Public/Private Urban Beach," ANY: Architecture New York 1 (July/August 1993): 48-53; "David Mohney, "Seaside and the Real World: A Debate on American Urbanism," ANY: Architecture New York 1 (July/ August 1993): 6-9. Also see, Zachary Tate Porter, "Architecture $\neq$ Landscape: The Case Against Hybridization," in The Ethical Imperative: Proceedings of the 106th Annual ACSA Meeting, ed., A. Ameri and R. O'Neal Dagg (Washington, DC: ACSA Press, 2018).

9 Christopher Knight, "Art Review: 'Asco: Elite of the Obscure, 1972-1987' at LACMA," Los Angeles Times, September 9, 2011.

10 For more detailed analysis of the relationship between technology and political protest, see Philip N. Howard and Muzammil M. Hussain, Democracy's Fourth Wave? Digital Media and the Arab Spring (Oxford: Oxford University Press, 2013); and Zeynep Tufekci, Twitter and Tear Gas: The Power and Fragility of Networked Protest (New Haven, CT: Yale University Press, 2017).

11 See, for instance, Mike Lydon and Anthony Garcia, Tactical Urbanism Short-Term Action for Long-Term Change (Washington, DC: Island Press/Center for Resource Economics, 2015); and Jeffrey Hou, Insurgent Public Space: Guerilla Urbanism and the Remaking of Contemporary Cities (London: Routledge, 2010).

12 Adam Greenfield, "Uber, or: The Technics and Politics of a Socially Corrosive Mobility," The Site Magazine 39 (2018): 77.

\section{Greenfield, 74-76.}

14 Terry Eagleton, Walter Benjamin: Towards a Revolutionary Criticism (London: Verso, 1981), 148. Also see, Peter Stallybrass and Allon White, The Politics and Poetics of Transgression (London: Methuen, 1986).

15 Eagleton, Walter Benjamin, 148.

16 The phrase "illusion of continuity" is borrowed from David Ruy's introduction of Gilles Retsin's public lecture at SCl-Arc in 2018. For a more in-depth discussion of the emerging discourse on "discreteness," see Architectural Design 89, no. 2 (February 2019), guest-edited by Gilles Retsin and including essays by Jose Sanchez, Philippe Morel, and Mario Carpo, as well as a counterpoint by Neil Leach.

17 Pier Vittorio Aureli, The Possibility of an Absolute Architecture (Cambridge, MA: The MIT Press, 2011), 37.

18 In fact, there is a growing trend within contemporary architecture to delineate architecture's boundary with the city through the formal manipulation of the ground plane. For instance, OMA's Casa da Musica and Thomas Heatherwick's Seed Cathedral each feature an undulating ground surfaces that exaggerate the discontinuity between the building site and its surrounding urban context. In a similar way, Tom Wiscombe has theorized and designed a series of "ground objects," which physically separate architecture from the literal ground of the city. See Tom Wiscombe, "Discreteness, or Towards a Flat Ontology of Architecture," Project 3 (Spring 2014).

19 For instance, see Aldo Rossi, The Architecture of the City (Cambridge: Graham Foundation for Advanced Studies, 1982).

20 Jane Jacobs, The Death and Life of Great American Cities (New York: Random House, 1961), 35 